\title{
Philadelphia chromosome-negative non-Hodgkin's lymphoma occurring in Philadelphia chromosome-positive chronic myeloid leukemia: A case report and literature review
}

\author{
ZHENG-LEI SHEN ${ }^{1}$, LIE-FEN YIN ${ }^{2}$, WEN-WEN MAO ${ }^{3}$, JIN LIANG $^{1}$ and LING YANG ${ }^{2}$ \\ ${ }^{1}$ Department of Hematology, Yunnan Tumor Hospital, Kunming, Yunnan $650118 ;{ }^{2}$ Department of Hematology, \\ The Second Affiliated Hospital of Kunming Medical University, Kunming, Yunnan 650031; ${ }^{3}$ Department of Geriatrics, \\ Kunming Second People's Hospital, Kunming, Yunnan 650204, P.R. China
}

Received February 3, 2015; Accepted January 4, 2016

DOI: $10.3892 / \mathrm{ol} .2016 .4304$

\begin{abstract}
The current study reports the case of a patient with Philadelphia chromosome-negative $\left(\mathrm{Ph}^{-}\right)$non-Hodgkin's lymphoma (NHL) and chronic phase (CP) Philadelphia chromosome-positive $\left(\mathrm{Ph}^{+}\right)$chronic myeloid leukemia (CML) that also possessed characteristic enlarged lymph nodes. A lymph node biopsy resulted in the diagnosis of CP-CML, in addition to T-lymphoblastic cell NHL with negative break point cluster/Abelson tyrosine kinase fusion genes in the lymph node of the patient, which was diagnosed as $\mathrm{Ph}^{-}$NHL. A review of the literature was performed in the present study to investigate the genetic differences between $\mathrm{Ph}^{-} \mathrm{NHL}$ and $\mathrm{Ph}^{+}$ NHL in patients with CML. The median age of patients with NHL and CML was 41 years. The follow-up time of patients with $\mathrm{Ph}^{+} \mathrm{NHL}$ was significantly shorter (mean, $<6$ months) compared to the follow-up time of patients with $\mathrm{Ph}^{-} \mathrm{NHL}$ (mean, $>15$ months). Therefore the present study concludes that $\mathrm{Ph}^{+} \mathrm{NHL}$ may be more aggressive compared with $\mathrm{Ph}^{+}$ NHL. The present study suggests that additional studies are required to assess the clinical and genetic characteristics of NHL patients with CML.
\end{abstract}

\section{Introduction}

Chronic myeloid leukemia (CML) is a clonal proliferative disorder of hematopoietic stem cells that is characterized by the presence of the Philadelphia chromosome $(\mathrm{Ph})$ and break point cluster/Abelson tyrosine kinase (BCR/ABL) fusion genes (1). According to the 2008 World Health Organization

Correspondence to: Dr Lie-Fen Yin, Department of Hematology, The Second Affiliated Hospital of Kunming Medical University, 112 Kunrui Road, Kunming, Yunnan 650031, P.R. China E-mail: ylfynkm@126.com

Key words: non-Hodgkin's lymphomas, fusion gene, chronic myelogenous leukemia, philadelphia chromosome classification of hematopoietic tumors (2), CML has a triphasic clinical presentation, consisting of chronic phase (CP), accelerated phase (AP) and blast crisis (BC) (3).

Extramedullary $\mathrm{BC} \mathrm{Ph}^{+} \mathrm{CML}$ is infrequent (4) and there are extremely few cases described in the literature (5). At present, it is simple to detect the origin of blast cells using standard cytogenetic analysis, reverse transcription polymerase chain reaction (RT-PCR) and fluorescence in situ hybridization (FISH). However, due to the rarity of patients with extramedullary $\mathrm{BC} \mathrm{Ph}^{+} \mathrm{CML}$, little is known concerning the clinical and genetic characteristics of T-lymphoblastic non-Hodgkin's lymphoma (NHL) (T-LBL) with CML. The present study reports the case of a patient with $\mathrm{Ph}^{-} \mathrm{NHL}$ and $\mathrm{CML}$, and reviewed the literature review on the clinical and genetic features of similar patients.

\section{Case report}

A 28-year-old man presented to the Department of Hematology of the Yunnan Tumor Hospital (Kunming, Yunnan, China) in November 2012 with bilateral axillary and neck swellings that had been present for the past month, and a low fever, slight weight loss and night sweats that had been present for the previous 2 weeks. The patient possessed no history of bone or abdominal pains and had received no treatment prior to the onset of the symptoms. Physical examination revealed that the patient had multiple enlarged lymph nodes on the bilateral cervical, axilla, inguinal and epitrochlear regions $(\leq 10 \mathrm{~cm}$ in diameter), slight splenomegaly and no hepatomegaly.

Routine blood tests revealed a white blood cell count of $23.0 \times 10^{3}$ cells $/ \mu 1$ (normal range, $4.0-10.0 \times 10^{3}$ cells $/ \mu 1$ ) with leukoerythroblastosis: band neutrophils, $17.0 \%$ (normal range, 16.4-32.1\%); segmented neutrophils, $36.0 \%$ (normal range, 4.2-21.2\%); basophils, $2.0 \%$ (normal range, 0.0-1.0\%); lymphocytes, $44 \%$ (normal range, $0.0-40.0 \%$ ); myeloblasts, $0.0 \%$ (normal range, $0.0-1.8 \%$ ); metamyelocytes, $1.0 \%$ (normal range, 0.4-3.9\%). Furthermore, an erythrocyte count of $4.6 \times 10^{6} \mathrm{cells} / \mu 1$ (normal range, $3.5-5.0 \times 10^{6} \mathrm{cells} / \mu \mathrm{l}$ ), a platelet count of $3.4 \times 10^{6}$ platelets $/ \mu 1$ (normal range, $1.0-3.0 \times 10^{5}$ platelets $/ \mu \mathrm{l}$ ), a hemoglobin level of $12.7 \mathrm{~g} / \mathrm{dl}$ (normal range, $11.0-16.0 \mathrm{~g} / \mathrm{dl}$ ) and a hematocrit level of $47.0 \%$ (normal range, 
40.0-50.0\%) were observed. A bone marrow smear identified serious granulopoiesis (granulocytes, 95\%; blast cells, 1.5\%) and extremely reduced activity of neutrophil alkaline phosphatase. Peripheral blood and bone marrow investigations demonstrated that the patient possessed typical CML-CP. Cytogenetic analysis of peripheral blood cells revealed the presence of a $\mathrm{Ph}$ chromosome in all 20 metaphase cells of a standard type that were analyzed. In total, 16 of the metaphase cells appeared to possess a double $\mathrm{Ph}$ chromosome and chromosomes 8 and 19.

RT-PCR (using a ready-to-use Genequality BCR-ABL kit (AB ANALITICA s.r.l, Padova, Italy) of the RNA obtained from the bone marrow cells of the patient revealed the presence of BCR/ABL gene rearrangements. The BCR and ABL genes were identified in the bone marrow cells by FISH [using a Vysis LSI BCR/ABL dual color dual fusion translocation probe (Abbott Molecular, Inc., Des Plaines, IL, USA) and a 4',6-diamidino-2-phenylindole counterstain (Sigma-Aldrich, St. Louis, MO, USA)], which revealed the presence of the transcript for BCR/ABL p210 (positive rate, $98 \%$ ) and no argininosuccinate synthetase fusion signal. Immunophenotyping was performed using immunohistochemistry on biopsy slides, and the results revealed that the blast cells were positive for cluster of differentiation (CD)3, CD7 and terminal deoxynucleotidyl transferase (TDT), and did not express myeloperoxidase, indicating that the $\mathrm{T}$ cell phenotypic lineage was typical of lymphoma. RT-PCR was performed from the aspirate of the lymph node, and the results revealed a transcript that was negative for BCR/ABL p210. Therefore, a final diagnosis of $\mathrm{Ph}^{-} \mathrm{NHL}$ non-extramedullary phenotypic T-blast cell lymphoma and CML-CP was established.

The patient was treated daily with intramuscular human lymphoblastoid interferon- $\alpha$ at a dose of 6 million IU. Hydroxyurea for microantibody treatment or stem cell transplantation was not economically feasible for the patient. Subsequent to chemotherapy, partial remission was obtained and the condition of the patient remained stable in CML-CP. The etoposide (100 mg/d; days 3-5), cyclophosphamide $\left(750 \mathrm{mg} / \mathrm{m}^{2}\right.$; day 1$)$, doxorubicin $(50 \mathrm{mg} / \mathrm{m} 2$; day 1$)$, vincristine $\left(1.4 \mathrm{mg} / \mathrm{m}^{2}\right.$; day 1) and predonisone [60 $\mathrm{mg} / \mathrm{m}^{2}$; days $\left.1-5\right]$ regimen was administered 2 months later for the enlarged lymph nodes of the patient.. Complete remission was not obtained. In total, 4 weeks later, the patient demonstrated progressive disease with organomegaly and left the hospital, and was lost to follow-up.

\section{Discussion}

The present study described the case of a young male patient with CML that developed an extramedullary BC in bilateral axillary and lymph node swellings. The bone marrow of the patient demonstrated CML-CP and a biopsy of the lymph node of the neck indicated that the patient developed an extramedullary $\mathrm{BC}$ derived from $\mathrm{T}$ blast cell clones.

Partially due to the rarity of this condition, there is little information on the cellular origins, pathogenesis or clinical behavior of $\mathrm{Ph}^{-} \mathrm{NHL}$ with CML-CP (6). Lymph node enlargement in patients with CML may be due to blast cells originating from the lymphoid or myelo-monocytoid lineages (4). There are patients with NHL that exhibit the same genotype in the lymphoid neoplasms and CML, but there are also patients that exhibit different genotypes in the lymphoid neoplasms and CML. The present study reports the case of a patient belonging to the latter group. To the best of our knowledge, the present study is one of few clearly diagnosed cases of CML combined with $\mathrm{Ph}^{-}$NHL reported between 1980 and the present time $(3,7,8)$. A literature search of the electronic PubMed database (www.ncbi.nlm.nih.gov/pubmed; up to February 2015) was conducted using the terms 'chronic myelogenous leukemia', 'non-Hodgkin lymphoma', 'BCR/ABL' and 'Philadelphia chromosome'. This search reviewed the literature for cases of CML combined with NHL to investigate the genetic differences between patients with $\mathrm{Ph}^{-} \mathrm{NHL}$ and CML and those with $\mathrm{Ph}^{+}$NHL and CML (Table I) $(4,6-25)$. The present study concluded that, out of the 24 patients that were diagnosed with NHL and CML, 19 patients possessed $\mathrm{Ph}^{+}$ NHL and 5 patients possessed $\mathrm{Ph}^{-}$NHL. The median age of patients with NHL and CML was 41 years.

Hashimoto et al (24) investigated the phenotype in patients with T-LBL and revealed that $252 \%$ T-LBL tumor cells expressed CD79a, and TDT was expressed in 95\% of T-LBL cells. It was concluded that these findings were associated with the origin of T-LBL from immature or precursor lymphocytes. However, no studies have reported the origin of tumor cells in T-LBL. Notably, CML is a myeloproliferative stem cell disorder, which has the potential to proliferate into numerous lineages, including myeloid, lymphoid, erythroid, megakaryocytic, undifferentiated or multi-lineage $(4,9,26)$. The BCR/ABL fusion gene, which is present in CML, was also detected in the endothelial progenitor cells of CML patients in China in 2014, which suggests that CML may originate from hemangioblastic progenitor cells that may proliferate into blood and endothelial cells (27). In addition, it was demonstrated that the rearrangement of the BCR/ABL gene may occur at or even prior to the level of hemangioblastic progenitor cells. By contrast, Dorfman et al demonstrated that the median time of survival was 7 months for patients that developed an extramedullary $\mathrm{BC}$ following a diagnosis of CML (8).

The literature review in the present study revealed that the follow-up time of patients with $\mathrm{Ph}^{+} \mathrm{NHL}$ was significantly shorter (mean, $<6$ months) compared with the follow-up time of patients with $\mathrm{Ph}^{-} \mathrm{NHL}$ (mean, $>15$ months) (Table I), which suggests that $\mathrm{Ph}^{+} \mathrm{NHL}$ may be a more aggressive disease compared with $\mathrm{Ph}^{-} \mathrm{NHL}$. This finding suggests that all cases of NHL with CML may be one disease, without one being an accompanying or secondary cancer, and there may be a key factor, in addition to the BCR/ABL gene, that remains unidentified. In addition, a tumor cell may alter genetically between $\mathrm{Ph}^{+} \mathrm{NHL}$ and $\mathrm{Ph}^{-} \mathrm{NHL}$ during the progression of the disease.

It is challenging to achieve complete remission in patients with $\mathrm{Ph}^{+}$or $\mathrm{Ph}^{-} \mathrm{NHL}$ and CML (8). The efficacy of imatinib mesylate treatment in CML-CP patients is clear (26); however, in AP or BC CML phases, treatment remains controversial and is limited. Therefore, a more appropriate treatment, including allogeneic stem cell transplantation, should be offered to such patients. To the best of our knowledge, there has been one study of a patient that achieved complete remission by unmanipulated HLA-haploidentical blood and marrow hematopoietic stem cell transplantation in China (11). 


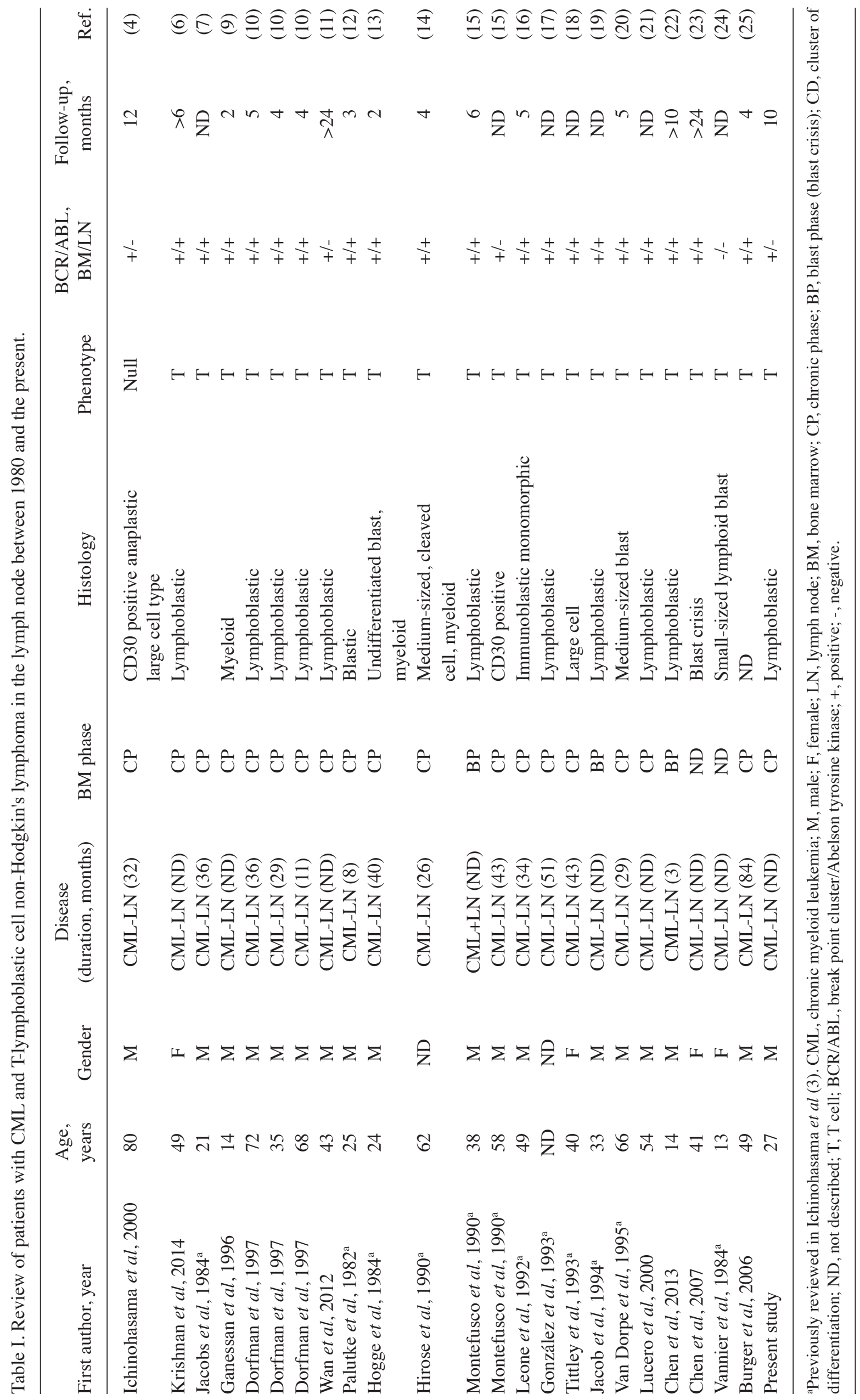


In conclusion, the present study suggests that additional studies are required to assess the clinical and genetic characteristics of NHL with CML.

\section{Acknowledgements}

The present study was supported partly by the Foundation of Yunnan Education Department (grant no. 09Z031). The authors thank Professor Yong-Chun Zhou from the Tumor Institute of Yunnan Province (The 3rd Affiliated Hospital of Kunming Medical University, Kunming, Yunnan, China) for performing the flow cytometry tests and to Miss Yun Chen from the Pathology Department of the Yunnan Tumor Hospital (Yunnan, China) for histological and morphological analysis.

\section{References}

1. Matsuda M, Morita Y, Shimada T, Miyatake J, Hirase C, Tanaka M,Tatsumi Y, Maeda Y and Kanamaru A: Extramedullary blast crisis derived from 2 different clones in the central nervous system and neck during complete cytogenetic remission of chronic myelogenous leukemia treated with imatinib mesylate. Int J Hematol 81: 307-309, 2005.

2. Swerdlow SH, Campo E, Harris NL, Jaffe ES, Pileri SA, Stein H, Thiele J and Vardiman JW (eds): WHO classification of tumours of haematopoietic and lymphoid tissues. In: IARC WHO Classification of Tumours. Vol 2. 4th edition. IARC Press, Lyon. 2008.

3. Al-Shehri A, Al-Seraihy A, Owaidah TM and Belgaumi AF: Megakaryocytic blast crisis at presentation in a pediatric patient with chronic myeloid leukemia. Hematol Oncol Stem Cell Ther 3: 42-46, 2010.

4. Ichinohasama R, Miura I, Takahashi N, Sugawara T, Tamate E, Endoh K, Endoh F, Naganuma H, DeCoteau JF, Griffin JD, et al: $\mathrm{Ph}$-negative non-Hodgkin's lymphoma occurring in chronic phase of Ph-positive chronic myelogenous leukemia is defined as a genetically different neoplasm from extramedullary localized blast crisis: Report of two cases and review of the literature. Leukemia 14: 169-182, 2000.

5. Sahu KK, Malhotra P, Uthamalingam P, Prakash G, Bal A, Varma N and Varma SC: Chronic myeloid leukemia with extramedullary blast crisis: Two unusual sites with review of literature. Indian J Hematol Blood Transfus: 1-7, 2014.

6. Krishnan S, Sabai K, Chuah C and Tan SY: Bilineal T lymphoblastic and myeloid blast transformation in chronic myeloid leukemia with TP53 mutation-an uncommon presentation in adults. Curr Oncol 21: e147-150, 2014.

7. Ganessan K, Goel R, Kumar K and Bakhshi S: Biphenotypic extramedullary blast crisis as a presenting manifestation of Philadelphia chromosome-positive CML in a child. Pediatr Hematol Oncol 24: 195-198, 2007.

8. Dorfman DM, Longtine JA, Fox EA, Weinberg DS and Pinkus GS: T-cell blast crisis in chronic myelogenous leukemia. Immunophenotypic and molecular biologic findings. Am J Clin Pathol 107: 168-176, 1997.

9. Wan D, Zhang S, Zhang C and Shao Y: A case of T lymphoblastic cell non-Hodgkin's lymphoma with CML by unmanipulated HLA-haploidentical blood and marrow hematopoietic stem cell transplantation. China J Hematol 3: 227-228, 2012.

10. Palutke M, Eisenberg L and Nathan L: Ph1-positive T lymphoblastic transformation of chronic granulocytic leukemia in a lymph node. Lancet 2: 1053, 1982.
11. Hogge DE, Misawa S, Testa JR, Leavitt RD, Pollak A and Schiffer CA: Unusual karyotypic changes and B cell involvement in a case of lymph node blast crisis of chronic myelogenous leukemia. Blood 64: 123-130, 1984.

12. Jacobs P and Greaves M: Ph1-positive T lymphoblastic transformation. Leuk Res 8: 737-739, 1984.

13. Hirose Y, Tachibana J, Takiguchi T, Tatsumi E and Konda S: T-lymphoblastic transformation of chronic myelocytic leukemia following T-lymphoblastic and myeloblastic biphenotypic crisis in the lymph nodes with rearrangement of bcr and TCR- $\beta$ genes. Eur J Haematol 45: 282-284, 1990.

14. Montefusco E, Mauro FR, Lo Coco F, Rondinelli B, Arcese W, Tabilio A, Monarca B, Alimena G and Mandelli F: Long-term remission of T-lymphoid extramedullary blast crisis of chronic myelogenous leukemia following allogeneic bone marrow transplantation. Haematologica 75: 391-393, 1990.

15. Leone G, La Rocca LM, Teofili L, De Candia E, Landolfi R, Sica S, Zini G, Zollino M and Tabilio A: Lymph node blast crisis in chronic myeloid leukemia mimicking T-immunoblastic lymphoma. Haematologica 77: 311-314, 1992.

16. González FA, Villegas A, Ferro MT, Cabello P, Morales D, Perez J and Martinez R: Usefulness of the rearrangement of the bcr/abl gene in extramedullary (lymph nodes) blast crisis diagnosed in chronic myeloid leukaemia. Br J Haematol 84: 351-352, 1993.

17. Tittley P, Trempe JM, van der Jagt R, Drouin J, Huebsch L, McLeish B and Cheng G: Occurrence of T-cell lymphoma in a patient with Philadelphia chromosome-positive chronic myelogenous leukemia with rearrangements of BCR and TCR- $\beta$ genes in the lymph nodes. Am J Hematol 42: 229-230, 1993.

18. Jacob A, Rowlands DC, Patton N and Holmes JA: Chronic granulocytic leukaemia presenting with an extramedullary $\mathrm{T}$ lymphoblastic crisis. Br J Haematol 88: 435-436, 1994.

19. Van Dorpe J, Van Damme S, Jacobs V, Van den Berghe H, Criel A, Michielssen P and Louwagie A: T-lymphoid extramedullary (lymphadenopathic) blast crisis in CML. Acta Clin Belg 50: 121-125, 1995.

20. Lucero G, Birman V, Colimodio E, Bertinetti CM, Kotliar N, Murolo P, Irusta O, Klimovsky J and Koziner B: Nodal T cell blast crisis in chronic myeloid leukemia. Leuk Lymphoma 39: 435-440, 2000.

21. Chen X, Rutledge JC, Wu D, Fang M, Opheim KE and Xu M: Chronic myelogenous leukemia presenting in blast phase with nodal, bilineal myeloid sarcoma and T-lymphoblastic lymphoma in a child. Pediatr Dev Pathol 16: 91-96, 2013.

22. Chen QS, Li JM, Sun HP and Shen ZX: T lymphoblastic lymphoma/acute lymphoblastic leukemiafrom blast crisis of chronic myelogenous leukemia-A case report and the review of literature. Shanghai Med J 30: 171-175, 2007.

23. Vannier JP, Bizet M, Bastard C, Bernard A, Ducastelle T and Tron P: Simultaneous occurrence of a T-cell lymphoma and a chronic myelogenous leukemia with an unusual karyotype. Leuk Res 8: 647-657, 1984.

24. Hashimoto K, Miura I, Chyubachi A, Saito M and Miura AB: Correlations of chromosome abnormalities with histologic and immunologic characteristics in 49 patients from Akita, Japan with non-Hodgkin lymphoma. Cancer Genet Cytogenet 81: 56-65, 1995.

25. Burger JA, Schmitt-Gräff A, Bürkle A, Seiler L and Finke J: Imatinib mesylate-induced long-term remission in extra-medullary T-cell lymphoid blastic phase of chronic myelogenous leukemia. Leuk Lymphoma 47: 2427-2430, 2006.

26. Wu JY, Huang L, Zhou JF, Pei RZ, Ma JX, Zhang PS, Liu XH, $\mathrm{Du} \mathrm{XH}$, Chen D, Sha KY, et al: Expression of BCR/ABL fusion gene in circulating endothelial cells from chronic myelogenous leukemia patients and its clinical significance. Zhongguo Shi Yan Xue Ye Xue Za Zhi 22: 927-931, 2014 (In Chinese).

27. Zonder JA and Schiffer CA: Practical aspects of the treatment of chronic myelogenous leukemia with imatinib mesylate. Curr Hematol Rep 2: 57-64, 2003. 